\title{
CORRESPONDENCE
}

\section{South African link}

SIR - Unfortunately the Science and Engineering Research Council (SERC) working party did not "examine the case" for renewing the agreement with the South African Council for Scientific and Industrial Research (CSIR) over the South African Astronomical Observatory (SAAO) (Nature 23 September, p.291). According to Professor Wilcock presenting the report at Sussex, their remit was to assess future demand for astronomical facilities in South Africa.

So the working party did not ask whether the link with CSIR, responsible for military as well as civil research for the South African state, is academically acceptable; did not ask whether the benefits to South African astronomy under the current agreement have been available to South African people irrespective of race and colour; and did not ask whether we should guard against the transfer of technology and technical knowhow that might assist the South African police and military, breaching at least in spirit the United Nations embargo. Nor were answers given at Sussex on how far the SAAO facilities could be available to individual astronomers without the formal agreement between the SERC and CSIR as state agencies being renewed. Perhaps because of the narrow remit, the working party did not look at scientific merit and take into account the comparatively low rating given to projects at SAAO by the scientific committees in recent years; rather, they advocated investment in additional instrumentation. Their promotional report in no way meets the need for a critical review of the South African collaboration, nor does it help astronomers in the United Kingdom to face up to their moral, political and scientific responsibilities.

University College, Cardiff, UK

MaX WaI.1.IS

\section{Cancer trends}

SIR - Gough and Gelband (Nature 15 April, p.598), commenting on the US cancer mortality graph reproduced in Nature on 4 March (p.4), suggest that the decline in "other" cancers since 1950, matched by a large increase in lung cancer to give a small overall rise, represents a real decrease in incidence not due simply to better diagnosis and treatment, attributing the fall in incidence of stomach cancers to changes in food preparation and preferences, and in cervical cancer to improved public health.

But there could be some direct connection between increasing incidence of lung cancer and decreases in other forms, if the population was genetically heterogeneous for susceptibility to cancer in general, with only the site of the growth determined by extrinsic carcinogens, in accordance with the "cancerproneness"' hypothesis'. A cancer-prone smoker would then be at serious risk of lung cancer, whereas a cancer-prone non-smoker would be as likely to get it in the stomach or uterus, or wherever another carcinogen was effective. But anyone who is not cancer-prone will not develop cancer in the lungs or anywhere else, however much he smokes, though he may die of some other smokingrelated disease: and, of course, 7 out of 8 of the heaviest smokers never do get lung cancer.

It follows that the more people take to smoking the more of the cancer-prone will die of lung cancer, although total cancer incidence will remain much the same. Actually, total cancer mortality should rise a bit (as it has, by 7 per cent over 30 years), since lung cancer kills more quickly than most, with little hope of cure.

There is evidence $^{2}$ that where particular geographical areas show an excess of one form of cancer (for example, between town and country, or in different London boroughs ${ }^{3}$ ), this is usually balanced by lower mortality from other forms, as is so also with occupational and racial groups, and between the sexes. In England and Wales in 1980, for example, the Registrar General reported 27,755 men but only 8,773 women dying of respiratory neoplasms (ICD 160-165); but for all cancers (ICD 140-208) there were 68,882 male and 60,359 female deaths, since 12,167 women but hardly any men died of breast cancer, and with more female genital cancers as well. So it looks as though a lot of cancerprone women, who would have got lung cancer had they smoked as much as men, are developing mammary and cervical cancers instead, incidentally with better prospects of survival. And these American trends are perhaps best explained by genetic cancerproneness as well.

There is an important practical point here, since recent claims that individual susceptibility to cytotoxic and carcinogenic agents can be diagnosed by tissue culture techniques ${ }^{4}$ suggest that it may become possible to ascertain relative cancer-proneness in advance, and to advise accordingly on smoking habits and employment.

C.V. GOODHART

University Museum of Zoology,

Cambridge, UK

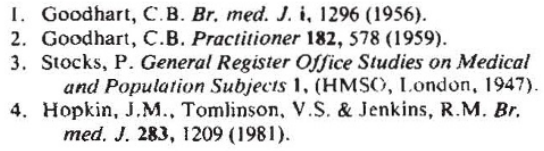

\section{Narrative style please}

SIR - Sir Peter Medawar ${ }^{1}$ comments on the "conventional" style (popular in the life sciences) as follows: "The layout of the text that has come to be regarded as conventional is that which perpetuates the illusion that scientific research is conducted by the inductive process. . A paper in the conventional layout may contain a section called 'Results' - a voluble pouring forth of factual information, usually with no connecting narrative to explain why one observation is made or one experiment done rather than another. Then follows a passage called 'Discussion' in which the author plays out the little charade. . .' (my emphasis).

In contradistinction, a recent paper in "continuous narrative" style by (for example) Charlton and Young 2 is not only of interest to fellow workers in their particular field but also to generalists, historians of chemistry and philosophers of science as a record of how their ideas developed during the research project. If one then takes into consideration the recent suggestion ${ }^{3}$ that even Francis Bacon was not an inductivist at heart, then the question might arise as to the possible inappropriateness of the "conventional" style in modern scientific journals.
Conventional methods of presentation have also been criticized by Norwich ${ }^{4}$, who states: "Experimental work is very often published in 'digested' form: raw data are not usually given. This may be due to author's preference, or due to editorial constraints, but in any case the lack of raw data often precludes the use of this paper in the evaluation of models,", (my emphasis).

The American Chemical Society has arranged a system whereby an author deposits supplementary experimental details with the editor under a "masthead reference".

If this were allied to manuscripts being submitted in the "readable" style, then primary journals might become more useful records of scientific research.

F.M. AKEROYD

Bradford College,

Bradford, Yorkshire, UK

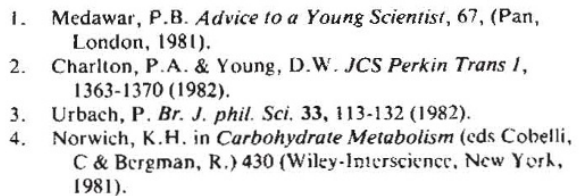

\section{Perchlorate hazard}

SIR - We reported last year ${ }^{1}$ on an explosion which occurred in our laboratories during the preparation of cobalt (II) perchlorate. Subsequent investigations have revealed no evidence to suggest that the material as normally prepared, hexaaquocobalt (11) perchlorate, is unstable in the absence of oxidizable material. Experiments indicate that the accident was probably caused by heating the solid hexaaquo compound to a temperature $\left(-150^{\circ} \mathrm{C}\right)$ at which partial loss of water of crystallization occurred with formation of a lower hydrate which is an endothermic compound capable of explosive decomposition. A fuller report has been published ${ }^{2}$

It seems that this type of hazard, which has not been previously recognized, may well exist with other metal perchlorates which normally exist in a stable hydrated state. Extreme caution is therefore urged in the handling of even pure metal perchlorates, to ensure that there is no risk of unintentional dehydration occurring. Even if this is done, it would be prudent not to subject perchlorates to mechanical shock unless the particular compounds involved are specifically known to be stable.

R.E. COOK P.J. RoBINSC:N

Department of Chemistry,

Manchester Polytechnic, Manchester, UK

1. Rubinson. P.J. Nature 293, 696 (1981).

2. Cook, R.E. \& Robinson, P.J. J. chem. Res. 267, 2772-2783 (1982).

\section{Human conception}

SiR - While entirely supporting Dr Edwards' work on in vitro fertilization and subsequent reimplantation of human embryos, and not wishing to become embroiled in the ethics of induced abortion, it seems to me that "the time . . . when human life begins"' (Nature 7 October, p.475) must be at fertilization. Then, and only then, does the embryo contain the potential (that is, the genetic information) to develop into a whole human being. 